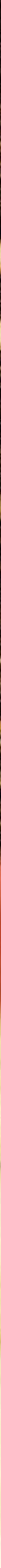

Editor I Letlhokwa George Mpedi 


\section{4 \\ Merry Christmas! \\ Terms and Conditions Apply}

Michele van Eck

Mr ST Nicholas

(also known as Santa Claus)

No $1 \mathrm{cnr}$ of Jolly \& Cheer Streets

The North Pole

Alaska

9277

20 December 2020

Dear Mr ST Nicholas,

RE:

LETTER OF DEMAND - NON-COMPLIANCE WITH THE SOUTH AFRICAN LEGISLATIVE FRAMEWORK

By way of introduction, we act on behalf of a non-profit organisation established to fight for the protection of individuals in the South African consumer market (our client). Our client has requested that we address this letter to you based on your established business practices in the South African market and your continued failure to comply with the country's legislative framework.

We draw your attention to the Consumer Protection Act 68 of 2008 (CPA), which came into effect on 1 April 2011. As you should be aware, in terms of section 5(1), the CPA applies to the supply of all goods and services within the boundaries of South Africa for consideration. Your business does indeed supply goods to various consumers in South Africa, and your receipt of cookies and milk on the $25^{\text {th }}$ of December 
annually is evidence of sufficient consideration received for your services. As none of the exceptions found in section 5(2) of the CPA applies to you, it is evident that the CPA regulates the sale and/or supply and/or provision of goods to your customers within South Africa.

We do, however, note that you have attempted to contract out of obligations imposed on you by the CPA, by including the following provision in your standard terms and conditions:

\begin{abstract}
"Although we will do everything in our power to comply with applicable legislation, including the Consumer Protection Act 68 of 2008 (CPA), we will not be held responsible (and you hereby waive any claim you may have against us) for any intentional or unintentional breach of the CPA, whether such a breach is caused by the negligence, gross negligence, wilful misconduct or the like of our founder ST Nicholas, any props, animals used to support our business operations such as (but not limited to) reindeer, bears and other fur-like creatures, as well as any systems, infrastructure and use of third party logistics support services, including the automated enterprise logistics filing systems (ELFS) and any other processing systems."
\end{abstract}

You are neither permitted to contract out of your responsibilities nor any rights that a consumer may be afforded under the CPA, which the abovementioned clause clearly attempts to do. This provision is expressly prohibited and invalid in terms of section 51 of the CPA. Therefore, we urge you to take the content of our letter seriously and remedy your non-compliance with the CPA as set out in this letter.

As part of your operations, we understand that your business solicits so-called orders in the form of customer 'wish lists' that are directed to your head office in the North Pole. Once orders are received by your automated enterprise logistics filing systems (known as ELFS) the origin of the order is identified and your customers' personal information is validated against your global database by the ELFS. After verification of your customers' identity, orders are processed based on whether the customer (often a minor) is on the 'naughty' or 'nice' list. 
It is not exactly clear how the ELFS determine whether a customer should be placed on the 'naughty' or 'nice' list, however, it is evident that such a differentiation is not established from some objective measurable but is rather based on your personal preferences and/or observations of your customers good or bad conduct the preceding year.

In terms of section 8 of the CPA, you may not unfairly discriminate between customers based on a discriminatory ground as listed in Chapter 2 of the Promotion of Equality and Prevention of Unfair Discrimination Act 4 of 2000 as well as section 9 of the Constitution. The CPA does, however, in terms of section 9(3) allow for some distinctions between the treatment of customers provided that it can be shown that the preference provided to the customer on the 'nice' list are firstly distinguishable from those customers found on the 'naughty' list and the general South African population. Secondly, that this distinction is intended to satisfy a specific need or interest that is unique to that particular group of customers found on the 'nice' list. There is no evidence that this exception applies to your business.

Our client finds it extremely disturbing that you would continue to differentiate between customers based on their status of being either good or bad and thereby group and place them on either the 'naughty' or 'nice' list. There is no clear indication or rationale for such a distinction, other than your observation of a person's conduct being either good or bad, which may very well be based on your judgment and/or personal approval or disapproval of your customers' lifestyle, morals, values and the like. We can, therefore, only conclude that your decision not to transact with customers on the so-called 'naughty' list is based on some unfair discriminatory reason and, therefore, must be a breach of section 8(2)(b) of the CPA. In fact, this very conduct is presumed to be unfair in terms of section 10(2)(a) of the CPA and we hereby call on you to provide tangible justification to show that such a distinction is reasonable and justifiable under the circumstances, failing which we reserve our client's rights to request the courts to compel you to do so. 
We are also advised that if your customers find themselves, for some unfortunate reason, on the 'naughty' list then their orders are discarded, alternatively destroyed, alternatively ignored but their personal information is retained on your database. Those orders from customers that are fortunate enough to find themselves on the 'nice' list can expect to have their orders processed and fulfilled on the $25^{\text {th }}$ of December. Unfortunately, your customers are only informed of whether their order would be fulfilled or not on the day of delivery.

Based on the retention of customers' personal information on your global database and the continued processing of this information by the ELFS, we also wish to draw your attention to the Protection of Personal Information Act 4 of 2013 ('POPIA'), which came into full force on 1 July 2020 and regulates the collection, storage, processing and destruction of personal information. It is clear that your business, and particularly the use of your ELFS, process your customers' personal information (which includes their names, surnames, age, gender, email addresses, physical addresses and postal addresses) in the form of collecting, storing, updating, modifying, amending and using your customers' personal information. Although you are domiciled in the North Pole Alaska, POPIA still applies to your business operations as you process information that is located in, or originates from South Africa via your ELFS, which can be described as an automatic processing system in terms of section 3(1) of POPIA.

We note that clause 16 of your standard terms and conditions confirms that you "... warrant that any customers personal information which is disclosed to us will be processed in a manner that complies with the Protection of Personal Information Act 4 of 2013, and that all customers are expected to cooperate with us in good faith in the transfer and processing of their personal information". We have serious doubts as to whether your ELFS are adhering to the eight pillars of responsible and lawful information processing set out in section 4(1) of POPIA being: accountability, processing limitation, purpose specification, further processing limitations, information quality, openness, security safeguards and data subject participation. In this regard, we wish to stress that section 9 of POPIA requires that you must process your customers' 
information lawfully so not to infringe on their privacy, and that section 10 requires that your customers' personal information may only be processed for a specific purpose that is relevant and not excessive. In this regard, section 18 of POPIA also requires that you take reasonably practical steps to ensure that your customers are made aware of the information that is being collected.

It is also evident that many of your customers are minors, being individuals younger than eighteen years of age, and in terms of sections $11(1)(a) 34$, and 35(1)(a) of POPIA you are not permitted to process their information without the consent of the responsible person of the minor in question. It is clear that neither yourself nor your ELFS solicits such consent from those responsible parties of your minor customers.

We are directed to demand from you, which we hereby do, your immediate compliance with the provisions of the CPA and POPIA as highlighted in this letter, and require that you present to us a confirmation of compliance by the $25^{\text {th }}$ of December 2020, failing which we may (amongst other things) direct our client to approach the National Consumer Tribunal, the National Consumer Commission, the courts or any other dispute resolution structure permitted by law. We, therefore, would urge you to take the content of this letter seriously and trust that this matter will be resolved without resorting to such extreme measures, especially over the Festive season.

Wishing you a very merry Christmas, and again reiterate that all of our client's rights remain strictly reserved.

Yours faithfully,

Signed electronically (in terms of section 13 of the Electronic Communications and Transactions Act 25 of 2002)

Mr. George Scrooge Admitted Attorney of the High Court of South Africa Partner at: Scrooge, Penny, Pinched \& Associates Inc. 